\title{
Secondary Bithalamic Ischemic Vascular Accident Has an Occlusion of the Artery of Percheron
}

\author{
Jennifer Nyangui Mapaga, Ibrahima Aïssata Camara*, Grass Aurelle Mambila Matsalou, \\ Pupchen Marilyse Gnigone, Nelly Diouf Mbourou, Annick Nsounda Mandzela, \\ Cherif Mohamadou Aidara, Kouna Ndouongo Philomène
}

Neurology Department of the University Hospital Center of Libreville (CHUL), Libreville, Gabon

Email: ^ibrahaissata@yahoo.fr

How to cite this paper: Mapaga, J.N., Camara, I.A., Matsalou, G.A.M., Gnigone, P.M., Mbourou, N.D., Mandzela, A.N., Aidara, C.M. and Philomène, K.N. (2019) Secondary Bithalamic Ischemic Vascular Accident Has an Occlusion of the Artery of Percheron. Open Access Library Journal, 6: e5169.

https://doi.org/10.4236/oalib.1105169

Received: January 7, 2019

Accepted: February 15, 2019

Published: February 18, 2019

Copyright $\odot 2019$ by author(s) and Open Access Library Inc.

This work is licensed under the Creative Commons Attribution International License (CC BY 4.0).

http://creativecommons.org/licenses/by/4.0/

\begin{abstract}
The bithalamic ischemic stroke secondary to percheron artery occlusion occupies a small place in the large ischemic stroke family, but its clinical polymorphism arouses patrician curiosity. We thus report 3 observations that explain the richness of this affection.
\end{abstract}

\section{Subject Areas}

Public Health

Keywords

Stroke, Bithalamic, Percheron's Artery

\section{Introduction}

Bithalamic infarction is a rare infarction secondary to occlusion of the percheron artery, an anatomical variant in the thalamo-mesencephalic vascular network described by Gérard Percheron, a French doctor, in 1977. Percheron's infarction was estimated in various studies of $0,1 \%$ to $2 \%$ of all ischemic strokes and $4 \%$ to $18 \%$ of all thalamic strokes [1]. The clinical picture is highly polymorphous due to the anatomical variability of the vascular territories and the interindividual variability of extension of Infarcted territories [2]. Because of its clinical polymorphism, it is difficult diagnosis on the only data of the clinical examination only the imagery notably the cerebral MRI makes the diagnosis [3]. 


\section{Observation 1}

This is a 72-year-old patient with insulin-dependent diabetes and dyslipidemia as cardiovascular risk factors. Its usual treatment is insulin and lipid-lowering. She is found on the ground by her daughter. Arrival at the emergency department, patient is sleepy, the blood pressure to $115 / 64 \mathrm{mmHg}$, the patient is afebrile. Neurologically, there was dysarthria, left ptosis and mydriasis in favor of incomplete III involvement, gait instability, discrete right hemiparesis, cognitive retardation, idiopathic $12 / 30$. It is not observed during the examination of abnormal movements. The brain scan is normal. Cerebral MRI coupled with angio-MRI reveals a staged involvement of the vertebrobasilar territory with hyper signals in the left paramedian mesencephalic region, in the bilateral thalamic region, probably related to an anatomical variation called percheron artery. There is no evidence of extra or intracranial thrombosis or occlusion. The ECG regains arrhythmia with cardiac arrhythmias due to atrial fibrillation. Transoesophageal ultrasound reveals no emboligenic anomaly. The Doppler of normal neck vessels. There is no biological abnormality. The treatment consisted of the introduction of a low molecular weight heparin anticoagulation relayed by Eliquis 5 $\mathrm{mg}$ twice a day, the management of vascular risk factors (hypertension, diabetes) and functional rehabilitation. The patient has recovered at the level of motor skills but cognitively recovery is not total (Figure 1).

\section{Observation 2}

Patient of 33 years hypertensive under treatment without notion of therapeutic nonobservance, admitted for a left hemicorporal deficit of brutal installation. In the story the patient describes that two weeks before the deficit, headaches in helmet without notion of nausea and vomiting associated with left hemicorporeal heaviness evolving in a febrile context. In front of the fevers it was automatic with antimalarials without modification of the signs. In front of the aggravation of the symptoms he consults to the urgencies then to transfer in the service of neurology. The clinical examination found a left pyramidal syndrome. As diagnostic hypothesis evoked an intracranial expansive process, cerebral thrombophlebitis, encephalitis. CT-CT coupled with TSA demonstrated bi thalamic hypodense in favor of percheron artery occlusion. The ECG has not found disturbances of cardiac rhythms, Doppler ultrasound of supra-aortic trunks is normal, and Doppler ultrasound finds left ventricular hypertrophy and left ventricular diastolic insufficiency. The evolution on the clinical level was favorable after a good management of the cardiovascular risk factors (Figure 2).

\section{Observation 3}

A 65-year-old hypertensive patient is found by her unconscious husband. On arrival at Glasgow Emergency Room 6.The patient is intubated ventilated transferred to intensive care unit. MRI brain showed ischaemic bithalamic stroke, no visible thrombus in the basilar trunk. She is extubated after 5 days and is trans- 
ferred to neurology. The clinical examination finds a conscious and mute patient, the archaic reflexes present in favor of a frontal syndrome. There is no deficit motor or abnormal movements. The ECG has highlighted an FA that was previously unknown. Normal transesophageal echography. The patient is put on anticoagulant. The evolution was marked by the persistence of the frontal syndrome (Figure 3).

\section{Discussion}

The thalamus is the largest of the nuclei of the gray matter of the cerebral hemispheres. Gray vascularization nucleus and complex function occupies a key place in the central nervous system and represents a mandatory relay of all sensory and sensory functions. It is subdivided into a number of nuclei that have functional specializations to treat particular types of information, connected to

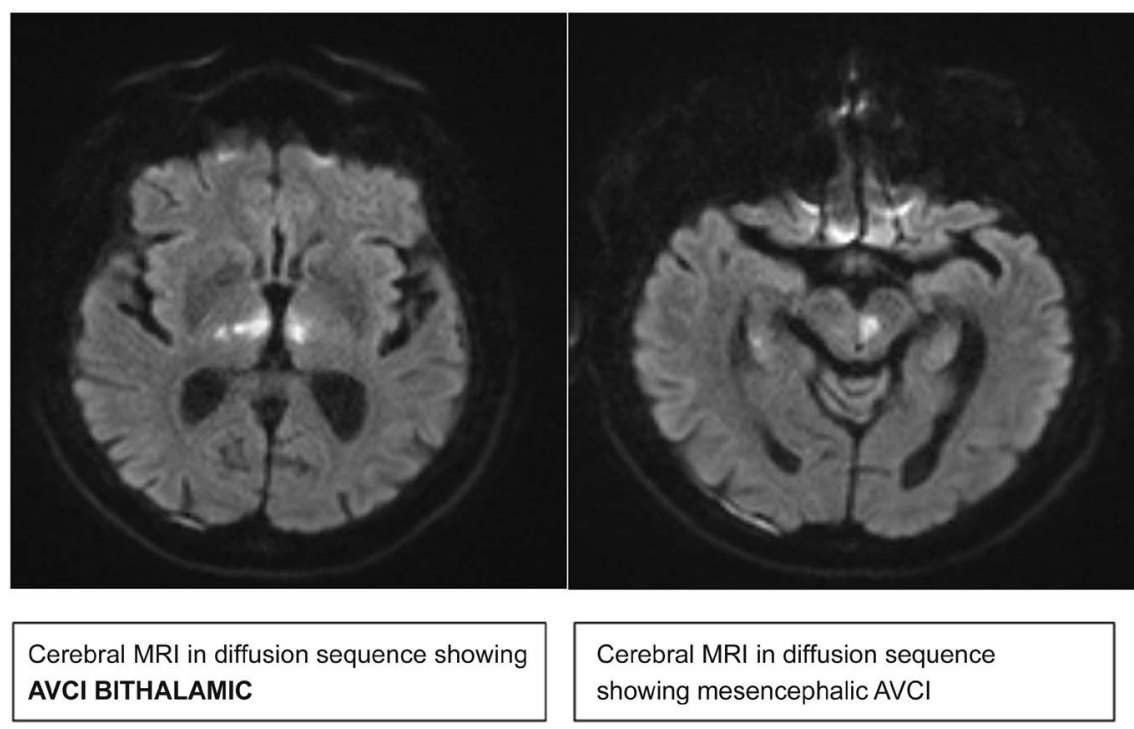

Figure 1. Image of observation 1.

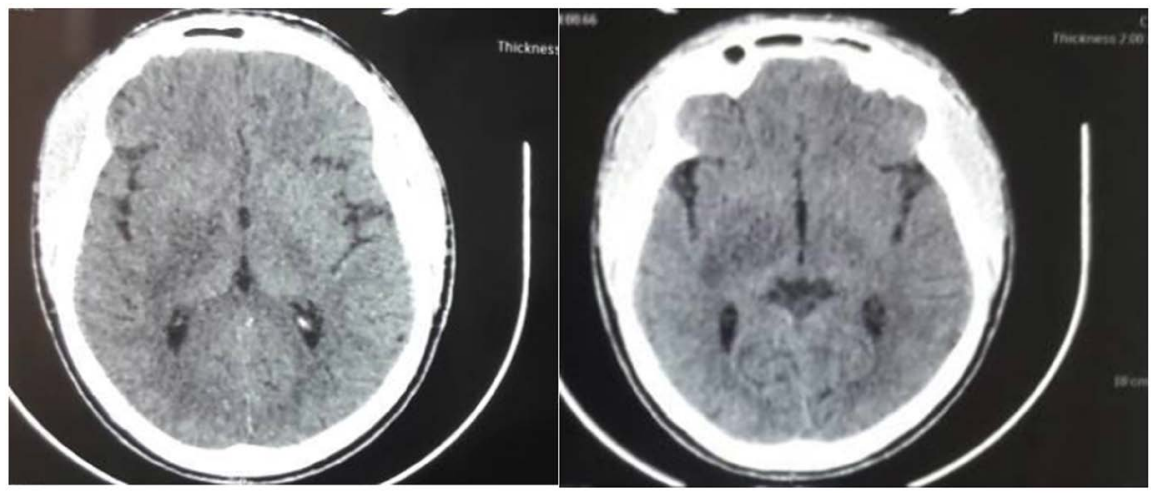

Cerebral CT: AVCI BITHALAMIC predominant onthe right by occlusion of the artery of

Figure 2. Image of observation 2. 


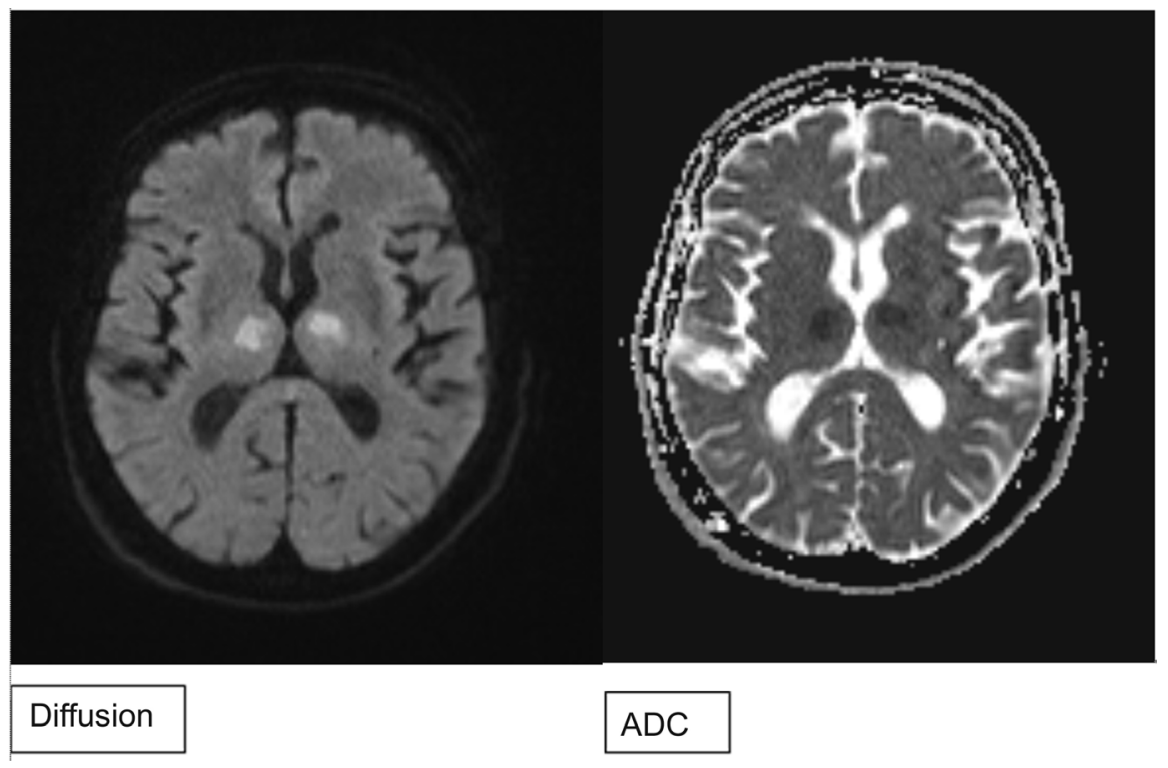

Figure 3. Image of observation 3.

the cerebral cortex, cerebellar pathways, limbic system, and basal ganglia [4]. The vascularization of the thalamus is dependent on the vertebrobasilar system. There are four major vascular territories in the thalamus: tuberothalamic, inferolateral, paramedian and posterior choroidal [5]. The paramedian thalamic or thalamo-perforating arteries feed the paramedian thalamus but also the medial areas of the upper part of the brainstem: the interpeduncular nucleus, the decussation of the superior cerebellar peduncles, the medial part of the red nucleus, the third and fourth nucleus of the cranial nerves, and the anterior part of the periaqueducal gray matter. Also the thalamo-perforating arteries arise either from the bifurcation of the basilar artery or from the initial part of the posterior cerebral artery, these paramedian arteries can be born from a single trunk, this common trunk carries the eponymous artery. Of percheron still called common trunk for the paramedian thalamic arteries, its occlusion is at the origin of a bilateral paramedian bithalamic infarction with or without myocentric infarction [6] [7] [8] [9]. Four anatomical variants of thalamus and mesencephalon perfusion have been described. Variant I: the most frequent, in which each perforating artery comes from each left and right posterior cerebral artery, variant II: it is asymmetrical, right and left perforating arteries arise from the same posterior cerebral artery without lateral preference, (frequency of $45 \%$ ), divided in turn into Type II A: born independently in the same posterior cerebral artery and Type II B: they are born from a common arterial trunk called the Percheron artery, which comes from the P1 segment of an artery Posterior cerebral palsy feeds the paramedian thalamus and the rostral mesencephalon bilaterally and finally variant III with several perforating branches emerging from a single arterial arch that joins the P1 segments of the two posterior cerebral arteries [6] [10] [11].

In one-third of the cases, the tubero-thalamic territory is dependent on the 
paramedian artery, thus extending the ischemic zone in case of occlusion of the percheron artery. The different functions of the thalamus and its vascularization explain the great variability of the clinical picture when it is reached. In case of percheron artery occlusion the signs frequently encountered are: disorders of consciousness, cognitive disorders and oculomotor disorders. Coma and hypersomnia are found in $47 \%$ and $29 \%$ of cases, however, it is observed in our series (case 1, case 2). Hypersomnia can be explained by the involvement of the intralaminar thalamic nucleus which forms with the posterior hypothalamus and the basal telencephalon the executive network of awakening under the control of three modulatory systems: the reticulo-hypothalamic-cortical pathway, the baso-cortical reticulo and the reticulo-thalamo-cortical pathway [12]. Memory disorders (anterograde and retrograde) are present in 63\% of cases, explained by the loss of connection between the anterior thalamus nucleus and the hippocampus connected by the Mamillo-thalamic tract when the vascularization of the tubero-thalamic territory is dependent on the vascularization of the paramedian territory [13]. In addition, other thalamus territories such as the dorsomedial nucleus and the medullary medulla oblongata of the thalamus can cause memory disorders. Confusion and behavioral disturbances in 55\% and $29 \%$ of cases. The oculomotor disorders concern the verticality of the gaze with a syndrome of $\mathrm{Pa}$ rinaud in $61 \%$ of the cases. Motor disorders and dysarthria are more rare $(13 \%$ and 29\%) In case of association with mesencephalic lesions we can observe the syndrome "mesencephalo-thalamic" or "thalamopedoncular" this syndrome is characterized by other oculomotor disorders, hemiplegia, cerebellar ataxia and abnormal movements as in our first observation (Figure 1) [14]. In addition, oculomotor disorders are related to a mesencephalon involvement, particularly by involvement of the III nucleus. The behavioral disturbances suggestive of a frontal syndrome are justified by the interruption of the thalamo-fronto-limbic loop in case of involvement of the tubero-thalamic territory explaining the frontal syndrome observed in our last clinical case. The associated sensory de fi cits are explained by the involvement of the middle part of the posterior ventral thalamic nucleus which is dependent on the paramedian or inferolateral vascular territory. The language disorders can be seen in the thalamus attack is found on the one hand the akinetic mutism which is secondary bilateral thalamococcal disease and secondly phasic disorders that are a subject of debate. Multiple thalamic nuclei (e.g., pulvinar, intralaminar nuclei, and ventral nuclei) are involved in language through their connectivity. Thalamic aphasia secondary to ischemic lesions occurs mainly with lesions of the tuberothalamic artery and less frequent with lesions of the paramedian arteries most often bilateral [15].

The low sensitivity of the CT makes diagnosis of infarction PDO difficult. Diffusion weighted MRI is the imaging modality of choice. However, PDO is rarely visualized on MR angiography, and lack of visualization does not exclude its presence [16] [17]. Small artery disease and emboligenic heart disease are considered to be the most common stroke mechanisms [18]. In view of its clinical polymorphism, several pathologies are under differential diagnosis, such as 
Creutzfeldt-Jakob disease, Gayet-Wernicke encephalopathy, thrombophlebitis of the internal cerebral veins, extrapontine myelinolysis [19].

\section{Conflicts of Interest}

The authors declare no conflicts of interest regarding the publication of this paper.

\section{References}

[1] Lazzaro, N.A., Wright, B., Castillo, M., Fischbein, N.J., Glastonbury, C.M., Hildenbrand, P.G., et al. (2010) Percheron Infarction Artery: Imaging Models and Clinical Spectrum. American Journal of Neuroradiology, 31, 1283-1289. https://doi.org/10.3174/ajnr.A2044

[2] Four, A., Roland, G., Benabdelmoumene, N., Hovsepian, M., Melenotte, C., Rossi, P., Frances, Y. and Granel, B. (2014) A Rare Cause of Stroke. The Journal of Internal Medicine, 35, 212-213.

[3] Lamboley, J.L., Le Moigne, F., Have, L., Tsouka, G., Drouet, A., Salamand, P. and Guilloton, L. (2011) Occlusion of Percheron's Artery: Difficulties of Clinical Diagnosis and Place of MRI. About Six Cases. Journal of Radiology, 92, 1113-1121. https://doi.org/10.1016/j.jradio.2011.08.007

[4] Tatu, L. (2013) The Thalmus: Morphological Aspects. The Letter of the Neurologist. Vol. XVII-No. 9, 286-287.

[5] Cassourret, G., Prunet, B., Sbardella, F., Bordes, J., Maurin, O. and Boret, H. (2010) Ischemic Stroke of the Artery of Percheron with Normal Initial MRI: A Case Report. Case Reports in Medicine, 425, 734. https://doi.org/10.1155/2010/425734

[6] Godani, M., Auci, A., Torri, T., Jensen, S. and Sette, D.M. (2010) Coma with Vertical Palsy Gauze: Relevance of Angio-CT in Acute Percheron Artery Syndrome. Case Reports in Neurology, 2, 74-79. https://doi.org/10.1159/000315835

[7] Lamot, U., Ribaric, I. and Popovic, K.S. (2015) Artery of Percheron Infarction: A Review of Literature with a Case Report. Radiology and Oncology, 49, 141-146.

[8] Tatu, L. (2014) Arterial Blood Supply of the Thalamus. The Neurologist's Letter Flight, XVIII-No. 5, 170-171

[9] Tilfine, C., Azdad, O., Omor, Y., Amil, T. and Radouane, B. (2016) Bithalamo-Mesencephalic Infarction by Occlusion of the Percheron Artery. Journal of Neuroradiology, 43, 100. https://doi.org/10.1016/j.neurad.2016.01.075

[10] Percheron, G. (1976) Arteries of the Human Thalamus: II. Arteries of the Paramedianthalamic Territory of the Communicating Basilar Artery. Revista de Neurología, 132, 309-324.

[11] Amin, O.S.M., Shwani, S.S., Zangana, H.M., Hussein, E.M.H. and Ameen, N.A. (2011) Bilateral Thalami Paramedian Infarction: A Report of Two Cases of Percheron Occlusion Artery and Review of the Literature. BMJ Case Reports. https://doi.org/10.1136/bcr.09.2010.3304

[12] Bridoux, A. and Monaca, C. (2010) Normal Sleep and Neurobiology. The Pharmacologist's Letter, 24.

[13] Danet, L., Barbeau, E.J., Eustache, P., Planton, M., Raposo, N., Sibon, I., Albucher, J.F., Bonneville, F., Peran, P. and Pariente, J. (2015) Thalamic Amnesia after Infarction: The Role of the Mammillothalamic Tract and Mediodorsal Nucleus. Neurolo$g y$, 85, 2107-2115. https://doi.org/10.1212/WNL.0000000000002226 
[14] Lazzaro, N.A., Wright, B., Castillo, M., Fischbein, N.J., Glastonbury, C.M., Hildenbrand, P.G., et al. (2010) Percheron Infarction Artery: Imaging Models and Clinical Spectrum. American Journal of Neuroradiology, 31, 1283-1289. https://doi.org/10.3174/ajnr.A2044

[15] Cesaro, P., Rieu, D. and Hollat (2006) The Thalamic Syndrome EMC. Neurology, 17-037-F10.

[16] Matheus, M.G. and Castillo, M. (2005) Imaging of Bilateral Acute Paramedian Thalamic and Mesencephalic Infarcts. American Journal of Neuroradiology, 24, 8.

[17] Changa, Y.-M. and Fan, Y.-K. (2015) Artery of Percheron Occlusion in an Elderly Male: A Case Report. Journal of Clinical Medicine Research, 7, 126-128. https://doi.org/10.14740/jocmr2009w

[18] Arauz, A., Patiño-Rodriguez, H.M., Vargas-Gonzalez, J.C., Arguelles-Morales, N., Silos, H., Ruiz-Franco, A. and Ochoa, M.A. (2014) Clinical Spectrum of the Artery of Percheron Infarct: Clinical-Radiological Correlations. Journal of Stroke and Cerebrovascular Diseases, 23, 1083-1088.

https://doi.org/10.1016/j.jstrokecerebrovasdis.2013.09.011

[19] Zhou, Y.X., Fox, D., Anand, A., Elhaj, A., Kapoor, A., Najibi, F., et al. (2015) Artery of Percheron Infarction as an Unusual Cause of Korsakoff's Syndrome. Case Reports in Neurological Medicine, 1-8. https://doi.org/10.1155/2015/927809 